\title{
RESULTADOS DE APRENDIZAJE EN LA ARAUCANÍA. LA BRECHA DE GÉNERO EN EL SIMCE Y EL ANDROCENTRISMO EN EL DISCURSO DE DOCENTES DE LENGUAJE Y MATEMÁTICA ${ }^{1}$
}

\author{
María Cecilia Fernández ${ }^{2}$ \\ Scarlet Hauri ${ }^{3}$
}

\section{RESUMEN}

Este artículo presenta los resultados de una investigación que analizó la brecha de género en la prueba Simce de Matemática y Lectura entre los años 2006 y 2014 en estudiantes de $4^{\circ}$ año básico, $8^{\circ}$ año básico y $2^{\circ}$ año medio de la Región de La Araucanía en Chile. Los datos arrojaron que en Matemática la brecha de género tiende a disminuir, mientras que en Lenguaje presenta un incremento sostenido. Además, las variables área geográfica y grupo socioeconómico del establecimiento educacional, como también la pertenencia de los estudiantes al pueblo mapuche, operan como puntos de intersección que profundizan la desigualdad de género. En la fase cualitativa se analizaron los discursos de docentes de Lenguaje y Matemática de ocho establecimientos, desde el Modelo de Valoración. Se concluye que los educadores identifican habilidades diferenciadas en niños y niñas para el desempeño de las asignaturas. Así, en matemática predominan los JUICIOS de Estima Social de Capacidad para valorar a los niños y los de Tenacidad en la evaluación de las niñas. Por otra parte, el rendimiento en Lenguaje se explica con significados de AFECTO asociados con interés y motivación. Finalmente, las expectativas de los docentes respecto de sus estudiantes están asociadas con la división de roles de género.

Palabras clave: androcentrismo, brecha de género, estudios del discurso, modelo de valoración, Simce.

1 Proyecto apoyado financieramente por CNED/Convocatoria de apoyo a la investigación en educación 2015.

2 Observatorio Regional, Universidad Católica de Temuco, Temuco, Chile. Contacto: maria.fernandez@uct.cl

3 Departamento de Trabajo Social, Universidad de la Frontera, Temuco, Chile. Contacto: scarlet.hauri.o@gmail.com 


\title{
LEARNING OUTCOMES IN LA ARAUCANÍA. THE GENDER GAP ON THE SIMCE TEST AND THE ANDROCENTRISM IN THE DISCOURSES OF LANGUAGE AND MATH TEACHERS
}

\begin{abstract}
This article presents results from research which analyzed the gender gap on the standardized test, Simce, for Math and Reading from 2006 to 2014, among 4th, 8th and 12th grade students, from the region of Araucania, Chile. The data show that in math, the gender gap tends to decrease, while in language it continues to increase. Additionally, the school's characteristics such as geographic location and socioeconomic level, and whether the students belong to the Mapuche community, together intensify gender inequality. In the qualitative phase, we analyzed teacher discourse in the areas of language and math in eight schools using the Appraisal Model. We conclude that the educators identify differentiated abilities among boys and girls regarding academic performance in these subjects. Thus, in math, the Judgement of Social Esteem of Ability predominates in the valuing of boys and Tenacity in the evaluation of girls. Moreover, language performance is explained by meanings of affect associated with interest and motivation. Finally, teachers' expectations of their students are associated with the division of gender roles.
\end{abstract}

Keywords: androcentrism, appraisal framework, discourse studies, gender gap, Simce.

\section{Introducción}

Los instrumentos que miden la calidad de la educación evidencian una brecha de género (en adelante BG) en los resultados de aprendizaje. En varios países del mundo, incluido Chile, los hallazgos concluyen que las mujeres logran mejores desempeños en lenguaje, mientras que los hombres dominan en matemática. También se ha constatado que la BG, particularmente la que afecta a las mujeres, no tiene el mismo comportamiento en las distintas sociedades, por lo que habría factores sociales y culturales que impactarían en los resultados (De la Rica y González, 2013; Del Río \& Strasser, 2013; Flores, 2007; Martínez, Martínez \& Mizala, 2015). De esta forma, se ha avanzado en desestimar los argumentos asociados al determinismo biológico que han dominado las explicaciones acerca de las desigualdades entre hombres y mujeres en los distintos campos del conocimiento (Perdomo, 2010).

En Chile, en concordancia con la tendencia mundial, las mujeres han mejorado sus indicadores de escolaridad, alfabetización, matrícula y egreso. No obstante, la escuela sigue reproduciendo estereotipos tradicionales de género que favorecen las desventajas en 

EL SIMCE Y EL ANDROCENTRISMO EN EL DISCURSO DE DOCENTES DE LENGUAJE Y MATEMÁTICA - M. C. Fernández y S. Hauri

la vida adulta (Guerrero, Provoste y Valdés, 2006). En este sentido, las niñas logran un desempeño igual o superior a los hombres cuando inician su proceso de enseñanza, situación que se revierte al concluir la educación media y se vuelve más evidente en las pruebas de ingreso a la universidad (Flores, 2007), así como también al elegir una carrera profesional.

En este artículo se informan los hallazgos de una investigación que analizó la BG que registra la Región de La Araucanía en el Sistema de Medición de la Calidad de la Educación (Simce) ${ }^{4}$, entre los años 2006 y 2014. En la fase cuantitativa se estudió el comportamiento de la brecha en $4^{\circ}$ año básico, $8^{\circ}$ año básico y $2^{\circ}$ año medio en matemática y lectura, en relación con las variables: área geográfica, dependencia administrativa y grupo socioeconómico del establecimiento. Además, se exploró la BG entre estudiantes mapuche y no mapuche. En una segunda etapa se entrevistó a docentes de Lenguaje y Matemática de ocho establecimientos con BG más y menos significativas. Para analizar la presencia de sesgos androcéntricos en el discurso se empleó el Modelo de Valoración (Martin, 2000; Martin \& Rose, 2007; Martin \& White, 2005; White, 2003), herramienta teórica y metodológica inscrita en la Lingüística Sistémica Funcional (Halliday, 1994; Halliday $\&$ Matthiessen, 2014).

Este estudio se desarrolló en una de las tres regiones que presentan más bajos desempeños en el Simce de Matemática. En el caso de Lectura los resultados son similares a la media nacional, con una significativa tendencia a la baja en $8^{\circ}$ año básico y en $2^{\circ}$ año medio. Estos resultados se ven afectados por las desventajas sociales y económicas que vive la región. Según la Encuesta CASEN 2015, La Araucanía sigue siendo la región más pobre de Chile (Ministerio de Desarrollo Social, 2016). A lo anterior se suman los altos índices de población rural y de población mapuche que vive en situación de pobreza.

Las preguntas que guiaron este estudio fueron las siguientes: ¿Cuál ha sido el comportamiento de la BG en La Araucanía en el

4 El Simce es el instrumento oficial de medición de la calidad de la educación en Chile. 
Simce de Matemática y Lectura en $4^{\mathbf{0}}$ año básico, $8^{\mathbf{0}}$ año básico y $2^{\circ}$ año medio entre los años 2006 y 2014? ¿Cómo inciden el área geográfica, la dependencia administrativa y el grupo socioeconómico del establecimiento en la BG? ¿Qué relación se observa entre la BG y la pertenencia de los estudiantes al pueblo mapuche? ¿Hay alguna relación entre la BG del establecimiento y la existencia de sesgos androcéntricos en el discurso de los docentes? ¿Cómo se expresan los sesgos androcéntricos en el discurso de docentes de Matemática y Lenguaje?

Este artículo se organiza en cuatro apartados. El primero contiene un marco teórico que desarrolla el concepto de androcentrismo y expone los principales avances en la discusión referida a la BG en los resultados de aprendizaje. En este mismo apartado se presenta el Modelo de Valoración como herramienta útil para el estudio del androcentrismo en el discurso. En la segunda parte se explica la metodología y el procedimiento de investigación. En tercer lugar se presentan y discuten los resultados derivados del análisis cuantitativo y cualitativo y, finalmente, se ofrecen conclusiones y recomendaciones surgidas del estudio.

\section{Marco teórico}

\subsection{Androcentrismo y educación}

En la escuela se despliega un amplio repertorio de discursos que están mediados por las ideologías dominantes que organizan la vida social (Torres, 1998). Tal como la escuela juega un rol en la reproducción de la desigualdad de clase (Althusser, 1976; Gramsci, 1981) y en la reproducción cultural (Apple, 1986; Bernstein, 1990; 1998; Bourdieu y Passeron, 1998), también contribuye a la estratificación de género. Así, el estudio de currículos oficiales en distintos países del mundo demuestra que la escuela aporta conocimientos, habilidades y expectativas diferenciadas para hombres y mujeres (Díaz, 2003).

En La Araucanía, la discriminación de género se profundiza debido a factores como los altos índices de pobreza y ruralidad. Por otra parte, la pertenencia al pueblo mapuche también opera como 
un factor de exclusión. Al respecto, un estudio desarrollado en Chile concluyó que las formas más recurrentes de discriminación percibidas por personas mapuche son los sobrenombres, comentarios, chistes y burlas, expresados verbalmente en servicios públicos, en el trabajo y en el ámbito educacional (Merino, Quilaqueo y Saiz, 2008). En el sistema escolar, en tanto, se constató que los docentes tienen un prejuicio étnico hacia estudiantes indígenas, traducido en precepciones negativas respecto de sus habilidades lingüísticas, sus recursos cognitivo intelectuales y su disposición al aprendizaje (Becerra, 2011).

Una forma de perpetuar el orden social de género es a través del discurso androcéntrico en el sistema escolar. El androcentrismo es un enfoque unilateral que considera lo masculino como medida de todas las cosas y generaliza esos resultados como verdades universales para hombres y mujeres (Sau, 2000). A la vez, se trata de una perspectiva que menosprecia el rol de las mujeres y sus funciones asociadas con la reproducción, la producción de bienes de consumo familiar y todo lo que representa el mundo privado (Moreno, 2006). El enfoque androcéntrico remite a aspectos que permiten entender la desigualdad social, económica y sexual a partir del papel que hombres y mujeres ocupan en el centro del poder (Rovetto, 2010). Así, el androcentrismo ha dominado la construcción del conocimiento en general y, de manera particular, ha permeado los discursos difundidos en el sistema escolar.

\subsection{Desigualdades de género en los aprendizajes}

El Atlas mundial de la igualdad de género en la educación revela que en dos tercios de los países del mundo se ha alcanzado la paridad en educación primaria y secundaria, y que las tasas de matrícula femenina logran mayor incremento que la masculina. Sin embargo, una vez escolarizadas, las niñas enfrentan desventajas relacionadas con trato discriminatorio, acoso y/o presencia de estereotipos sexistas en los contenidos pedagógicos (Organización de las Naciones Unidas para la Educación, la Ciencia y la Cultura, Unesco, 2012). Los resultados de mediciones estandarizadas, nacionales e internacionales, concluyen que las políticas educacionales no han prestado suficiente atención 
a las cuestiones de género en la escuela. Prueba de ello es la brecha en los resultados de aprendizaje entre niños y niñas según áreas del conocimiento. Al respecto, existe evidencia de que los hombres superan a las mujeres en matemática, mientras estas últimas alcanzan mejores resultados en lectura (Unesco, 2012). Pese a que la ventaja de las mujeres en lectura es prácticamente universal, en matemática se observan diferencias entre distintas sociedades (Agencia de Calidad de la Educación, 2013). Así, aproximadamente en el 70\% de los países que participaron de la prueba PISA 2009, las niñas obtuvieron peores resultados que los niños en la prueba de Matemática (De la Rica y González, 2013). Esto indica que hay países que no presentan BG, o bien, que han logrado revertirla.

Según el Informe de Resultados del Estudio Internacional de Tendencias en Matemática y Ciencias (TIMSS) del 2011, la BG entre estudiantes chilenos es estadísticamente significativa en relación con los promedios internacionales: los niños superaron a las niñas en 9 puntos en $4^{\circ}$ año básico y en 15 puntos en $8^{\circ}$ año básico (Ministerio de Educación de Chile, Mineduc, 2012). Por otra parte, un análisis de la prueba PISA de Matemática aplicada a estudiantes chilenos en 2006, 2009 y 2012 reveló que aun cuando las mujeres han incrementado sus puntajes en un promedio de 15 puntos, persiste una brecha de 25 puntos a favor de los hombres (Agencia de Calidad de la Educación, 2013). Esta cifra sitúa a Chile, junto con Colombia, como el país con mayor BG del continente.

\subsection{Diferencias en los resultados de aprendizaje según sexo. ¿Biología o cultura?}

Históricamente las explicaciones acerca de los resultados de aprendizaje diferenciados por sexo han estado dominadas por argumentos basados en la distinción biológica. Así, fundamentos como el tamaño, forma y peso del cerebro, la localización de las funciones cognitivas y las hormonas sexuales han justificado la "superioridad intelectual" de los hombres. Sin embargo, estudios alternativos a esta corriente androcéntrica muestran que en contextos donde existe una estimulación igualitaria en el proceso de aprendizaje no se producen diferencias significativas entre niños y niñas (Perdomo, 2010). 
60 RESUltados DE APRENDIZAJE EN LA ARAUCANÍA. LA BRECHA DE GÉNERO EN EL SIMCE Y EL ANDROCENTRISMO EN EL DISCURSO DE DOCENTES DE LENGUAJE Y MATEMÁTICA - M. C. Fernández y S. Hauri

En los resultados de aprendizaje diferenciados por sexo intervienen habilidades específicas y factores ambientales. En relación con los primeros, las investigaciones concluyen que no hay diferencias en los niveles de inteligencia entre hombres y mujeres, pero sí hay habilidades distintas. Mientras en los hombres se identifican ventajas asociadas a tareas visuales espaciales, en las mujeres se observan habilidades asociadas a tareas verbales. Entre los factores ambientales destacan las experiencias de los estudiantes, las expectativas y los roles femenino o masculino (Niesser et al., 1996, en Cabezas, 2009). Estos últimos son los que han concentrado mayor atención, especialmente en el ámbito de las matemáticas.

Por otro lado, se sostiene que parte de las explicaciones de los resultados disímiles entre hombres y mujeres se encontraría en los contextos sociales y culturales. Así, en sociedades con mayores niveles de equidad de género las mujeres tienen mejores desempeños en matemática (De la Rica y González, 2013). Otro determinante cultural se relaciona con lo que se espera de niños y niñas en el sistema escolar. Al respecto, un estudio desarrollado en Chile reveló que los estudiantes de Pedagogía Básica tienen expectativas más bajas del rendimiento en Matemática de las niñas (Martínez et al., 2015). Una investigación acerca de creencias de preescolares chilenos en relación con las diferencias de género en las habilidades académicas, demostró que a los cinco años de edad niños y niñas ya tienen expectativas estereotipadas del desempeño escolar: niños y niñas creen que hombres y mujeres pueden tener buen rendimiento en Lenguaje, mientras que en Matemática creen que las mujeres tienen menos habilidades y peores rendimientos (Del Río \& Strasser, 2013). Además, los estudios que han analizado los factores asociados con los resultados del Simce en Matemática revelan la importancia de la variable género en los aprendizajes y la necesidad de implementar métodos de enseñanza que involucren de manera más activa y efectiva a las niñas (Calderón y Matus, 2013; Cerón y Lara, 2011).

La mayor parte de los factores asociados a la BG en los resultados de aprendizaje se concretan en el lenguaje. Así, estereotipos, creencias $y$, expectativas diferenciadas por sexo se cristalizan en los discursos y son posibles de identificar a partir del Modelo de Valoración. 


\subsection{El Modelo de Valoración (MVA) en el estudio del androcentrismo}

Los discursos no solo comunican sucesos, sino también pensamientos y sentimientos respecto de cosas, eventos o personas. En definitiva, transmiten las actitudes de hablantes o escritores y generan, a partir del potencial retórico del lenguaje, sentimientos de simpatía o desafección en quienes leen o escuchan (Oteíza, 2009).

El MVA, inicialmente desarrollado por Martin (2000), Martin y Rose (2007), Martin y White (2005), White (2003), inscrito en la Lingüística Sistémica Funcional (Halliday, 1994; Halliday \& Matthiessen, 2014), profundiza el estudio de la metafunción interpersonal del lenguaje en el nivel discursivo semántico. Así, constituye una herramienta teórica y metodológica que describe y explica las opciones de significados que ofrece el lenguaje para evaluar, adoptar posiciones, construir sujetos textuales, asumir roles, negociar relaciones y naturalizar posiciones intersubjetivas que son, finalmente, ideológicas (Kaplan, 2007). Para este efecto, el modelo plantea los dominios semánticos de ACTITUD, COMPROMISO y GRADACIÓN, de los cuales se derivan los subsistemas que se observan a continuación:

Figura 1. Dominios Semánticos del MVA

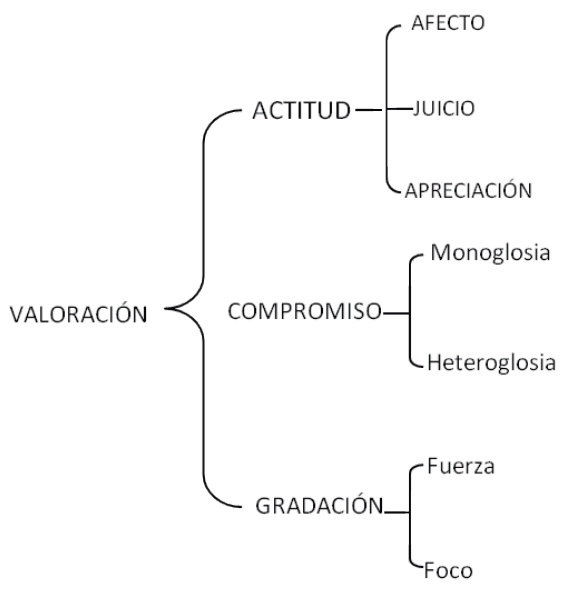

Nota: Figura basada en Martín y White (2005, p. 38). 

EL SIMCE Y EL ANDROCENTRISMO EN EL DISCURSO DE DOCENTES DE LENGUAJE Y MATEMÁTICA - M. C. Fernández y S. Hauri

La GRADACIÓN incluye las categorías de Fuerza y Foco para graduar los significados valorativos. La primera hace referencia a los recursos lingüísticos que intensifican la ACTITUD o, bien, suben o bajan el volumen de los sentimientos (Hood y Martin, 2005). Estos significados pueden ser construidos de manera explícita o indirecta, graduando la intensidad en una escala de baja a alta (bueno, muy bueno, notable). El Foco, por su parte, construye el valor de los enunciados indicando si son centrales, prototípicos o se sitúan en un estatus marginal (Kaplan, 2007). Así, se encarga de agudizar o suavizar un significado (un verdadero amigo/algo conmovida).

El COMPROMISO hace referencia a la fuente de la ACTITUD, es decir, identifica de dónde proviene la valoración (Martin \& White, 2005). Este sistema permite analizar los recursos lingüísticos empleados para posicionar intersubjetivamente la voz de hablantes o escritores y la posición que adoptan frente a sus propios enunciados y a otros puntos de vista que pueden ser ignorados o reconocidos de manera más o menos explícita.

El COMPROMISO incluye dos opciones semánticas contrapuestas. La monoglosia construye una proposición que no reconoce otros puntos de vista (Martin \& Rose, 2007; White, 2003), para lo cual comúnmente se emplean cláusulas declarativas que construyen afirmaciones consideradas no problemáticas y aceptadas por todos (Oteíza 2009; 2011). En la heteroglosia, en cambio, los productores textuales reconocen posiciones alternativas a las propias y abren posibilidades para negociar significados.

El sistema de ACTITUD se relaciona con los sentimientos. Incluye reacciones emocionales, juicios de conducta y evaluación de cosas (Martin \& White, 2005). La valoración puede adoptar valores positivos o negativos y expresarse de manera inscrita o evocada. Este dominio semántico se subdivide en los subsistemas de AFECTO, JUICIO y APRECIACIÓN:

- El AFECTO refiere a la disposición emocional del hablante (autorial) o de terceros (no autorial) hacia personas, eventos, fenómenos o cosas. Se concentra en significados de felicidad/ infelicidad, seguridad/inseguridad y satisfacción/insatisfacción. 
- El JUICIO alude a la evaluación de la conducta según normas de comportamiento socialmente establecidas. Este se subdivide en JUICIOS de Estima Social (Normalidad, Capacidad y Tenacidad) y de Sanción Social (Veracidad e Integridad).

- La APRECIACIÓN evalúa productos, procesos y entidades. Con categorías de Reacción, Composición y Valuación es posible valorar artefactos, textos o constructos abstractos como planes o políticas y objetos naturales o manufacturados.

El MVA constituye un marco propicio para estudiar el androcentrismo en el discurso, pues favorece el análisis de las percepciones subjetivas e intersubjetivas de género. Estas evaluaciones, provenientes de los propios hablantes o de otras voces, revelan posiciones más o menos androcéntricas expresadas en distinciones valorativas referidas a habilidades, rendimientos y expectativas de hombres y mujeres.

\section{Metodología}

En la primera etapa de la investigación se analizaron las bases de datos aportadas por la Agencia de Calidad de la Educación que contienen resultados del Simce por estudiante e información de las variables área geográfica y dependencia administrativa del establecimiento. Además, se incorporó una base de datos proporcionada por la Unidad de Estadísticas del Centro de Estudios del Ministerio de Educación que permitió analizar la relación entre BG y pertenencia de los estudiantes al pueblo mapuche entre los años 2010 y 2014. Para el estudio de la BG según grupo socioeconómico (GSE) del establecimiento se utilizó la clasificación que difunde el Simce para cada institución y nivel educacional 5 .

La unidad muestral estuvo conformada por todos los establecimientos de La Araucanía y la unidad de análisis la constituyeron todos los estudiantes de $4^{\circ}$ año básico, $8^{\circ}$ año básico y de $2^{\circ}$ año medio que consignan puntaje en el Simce de Matemática

5 La calificación por grupo socioeconómico (alto, bajo, medio, medio alto, medio bajo) se encuentra disponible en: http://www.simce.cl 

EL SIMCE Y EL ANDROCENTRISMO EN EL DISCURSO DE DOCENTES DE LENGUAJE Y MATEMÁTICA - M. C. Fernández y S. Hauri

y Lectura entre los años 2006 y 2014. El estudio de datos se basó en un análisis descriptivo de los puntajes, considerando las medias obtenidas en las pruebas, desagregadas por sexo para cada una de las variables analizadas.

En la segunda etapa se definió una muestra conformada por ocho establecimientos sobre la base de criterios de área geográfica, dependencia administrativa y grupo socioeconómico del mismo. De esta forma, se definieron cuatro grupos y por cada uno se seleccionó un establecimiento con BG significativa y uno sin BG o con tendencia a disminuir ${ }^{6}$ :

La muestra quedó conformada de la siguiente manera:

\begin{tabular}{l|l|l|l|l}
\hline & Grupo 1 & Grupo 2 & Grupo 3 & Grupo 4 \\
\hline Dependencia & $\begin{array}{l}\text { Particular } \\
\text { subvencionado }\end{array}$ & Municipal & $\begin{array}{l}\text { Particular } \\
\text { subvencionado }\end{array}$ & $\begin{array}{l}\text { Particular no } \\
\text { subvencionado }\end{array}$ \\
\hline Área geográfica & Rural & Urbano & Urbano & Urbano \\
\hline $\begin{array}{l}\text { Grupo } \\
\text { socioeconómico }\end{array}$ & Bajo & Bajo & Medio & Alto \\
\hline $\begin{array}{l}\text { Nivel } \\
\text { educaciona** }\end{array}$ & $4^{0}$ año básico & $8^{0}$ año básico & $8^{0}$ año básico & $2^{0}$ año medio \\
\hline $\begin{array}{l}\text { (+) brecha } \\
\text { género }\end{array}$ & $\begin{array}{l}\text { Escuela Particular } \\
\text { Catripulli, comuna } \\
\text { de Curarrehue }\end{array}$ & $\begin{array}{l}\text { Liceo James } \\
\text { Mundell, comuna } \\
\text { de Cholchol }\end{array}$ & $\begin{array}{l}\text { Instituto Claret, } \\
\text { comuna de Temuco }\end{array}$ & $\begin{array}{l}\text { Colegio Inglés } \\
\text { George Chaytor, } \\
\text { comuna de Temuco }\end{array}$ \\
\hline $\begin{array}{l}\text { (-) brecha } \\
\text { género }\end{array}$ & $\begin{array}{l}\text { Escuela Gabriela } \\
\text { Mistral, comuna } \\
\text { de Saavedra }\end{array}$ & $\begin{array}{l}\text { Liceo Reino de } \\
\text { Suecia, comuna } \\
\text { Saavedra }\end{array}$ & $\begin{array}{l}\text { Colegio } \\
\text { Emprender, } \\
\text { comuna de Temuco }\end{array}$ & $\begin{array}{l}\text { Colegio Altas } \\
\text { Cumbres, comuna } \\
\text { de Villarrica }\end{array}$ \\
\hline
\end{tabular}

* La variable nivel educacional corresponde al curso elegido para la selección de la muestra.

En cada establecimiento se entrevistó a un docente de Matemática y a uno de Lenguaje del nivel educacional correspondiente al criterio de selección.

6 Para definir los establecimientos se priorizaron comunas del Convenio de Desempeño para la Educación Superior UCT 1302, en el cual se enmarca este estudio (Cholchol, Curarrehue y Saavedra) y la comuna de Temuco, porque concentra la mayor matrícula regional. La comuna de Villarrica se incorporó por la resistencia de los establecimientos del grupo $\mathrm{N}^{\circ} 4$. 


\section{Análisis y discusión}

A continuación se presentan los principales hallazgos de la fase cuantitativa. Los resultados se exponen por sector de aprendizaje, dado que la BG presenta comportamientos distintos.

\subsection{BG en Matemática}

Los resultados revelan que la distancia entre niños y niñas de La Araucanía ha disminuido. Así, en $4^{\circ}$ año básico la brecha de seis puntos de 2006 se redujo en un 50\% en 2007 y se cerró en 2014. Este hallazgo es coincidente con lo que plantea Flores (2007), en términos que las mujeres tienen rendimientos similares o mejores que los hombres en los primeros años y que las brechas se amplían conforme avanza la escolarización. En $8^{\circ}$ año básico y $2^{\circ}$ año medio, la diferencia en los puntajes promedio de hombres y mujeres también tiende a disminuir:

Gráfico 1. Brecha regional de género $8^{0}$ año básico Matemática

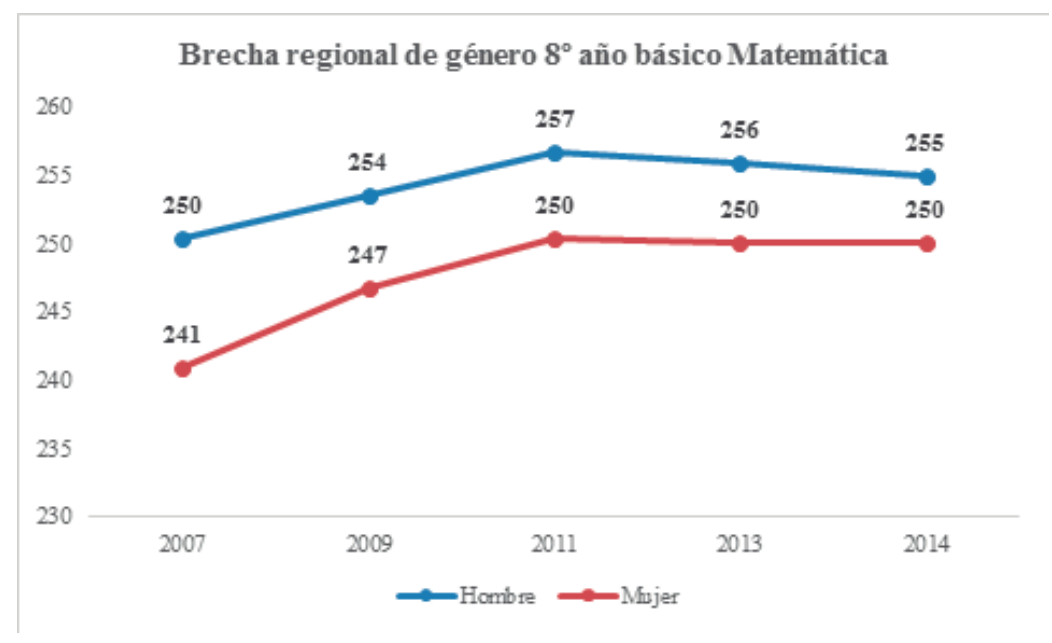

Fuente: Elaboración propia.

La BG de nueve puntos registrada el 2007 en $8^{\circ}$ año básico descendió a cinco puntos en 2014 (Gráfico 1). Además, las mujeres presentan un mayor aumento en el puntaje promedio entre $2007 \mathrm{y}$ 2014. El incremento en ambos sexos se produjo hasta la medición de 

EL SIMCE Y EL ANDROCENTRISMO EN EL DISCURSO DE DOCENTES DE LENGUAJE Y MATEMÁTICA - M. C. Fernández y S. Hauri

2011. En las dos evaluaciones posteriores las mujeres mantuvieron su puntaje y los hombres bajaron. Si bien este descenso es poco significativo, incide en la disminución de la $B G$. En $2^{\circ}$ año medio se presenta una situación similar:

Gráfico 2. Brecha regional de género $2^{0}$ año medio Matemática

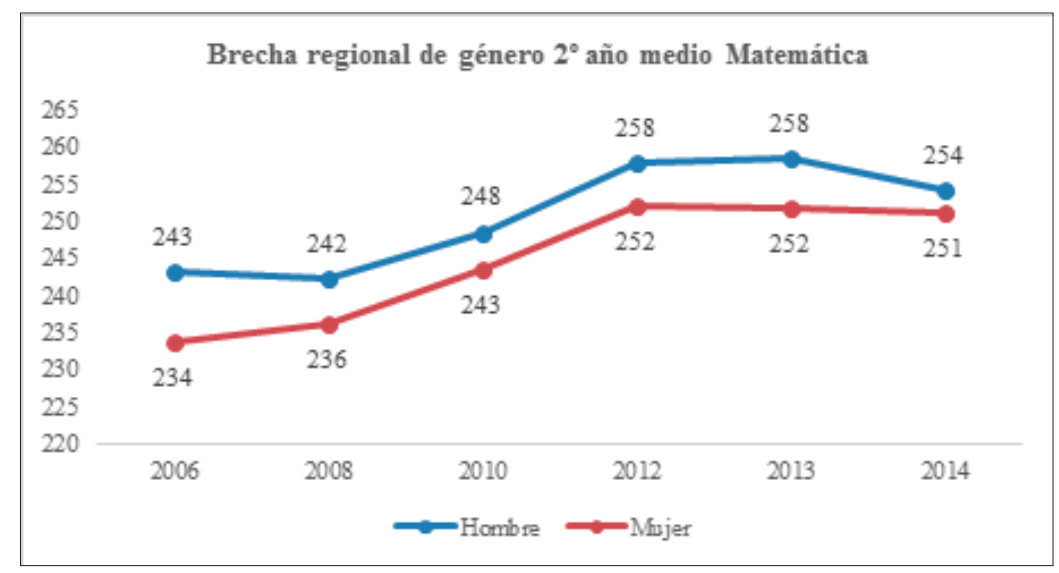

Fuente: Elaboración propia.

El Gráfico 2 muestra que el año 2014 los hombres experimentaron una baja de cuatro puntos respecto de la medición anterior. Este comportamiento contribuyó a que la BG se redujera en un 50\% entre los dos últimos años.

Del análisis de los datos se desprende que la disminución de la BG en $8^{\circ}$ año básico y $2^{\circ}$ año medio está -en parte- favorecida por la baja del puntaje obtenido por los hombres y por la mantención en el puntaje de las mujeres en las últimas evaluaciones.

\section{a. Brecha de género según área geográfica}

Los datos revelan que niños y niñas de establecimientos rurales tienen desempeños significativamente más bajos que quienes estudian en el sector urbano y que las estudiantes rurales experimentan la mayor desventaja. En el 2014 las niñas de $8^{\circ}$ año básico obtuvieron siete puntos menos que los niños de establecimientos de similares características, 24 puntos menos que las niñas de establecimientos urbanos y 29 puntos menos que los niños que estudian en la ciudad. 
Además, en ambos grupos la BG es significativa (cinco puntos o más), aunque es ligeramente superior en establecimientos rurales (Gráfico 3).

Gráfico 3. Brecha de género según área geográfica $8^{\circ}$ año básico Matemática

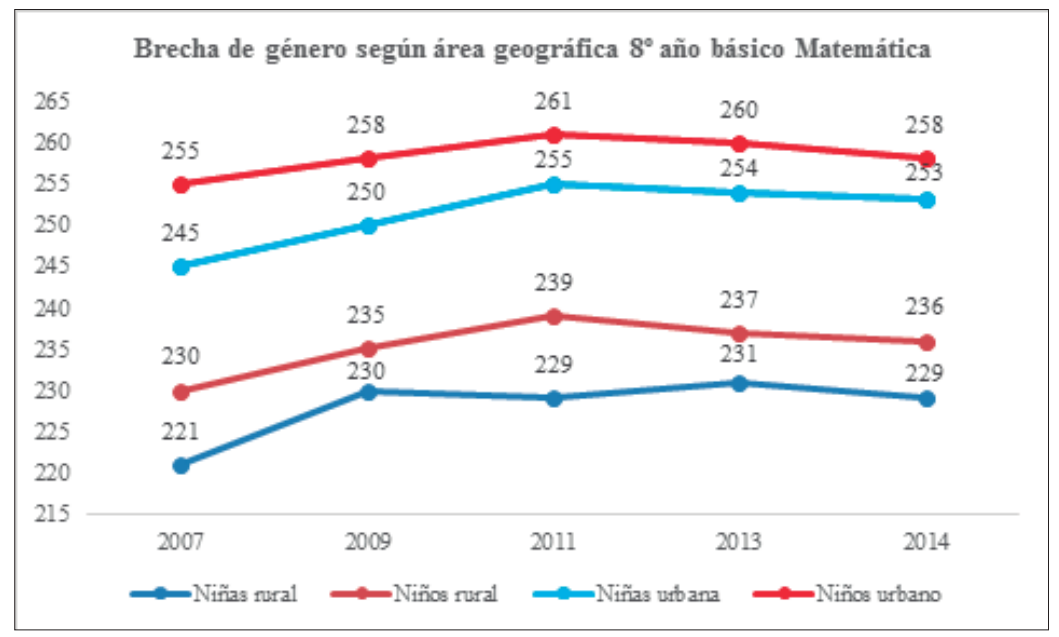

Fuente: Elaboración propia

A diferencia de $8^{\circ}$ año básico, entre adolescentes de $2^{\circ}$ año medio la BG es más alta entre estudiantes del sector urbano:

Gráfico 4. Brecha de género según área geográfica $2^{0}$ año medio Matemática

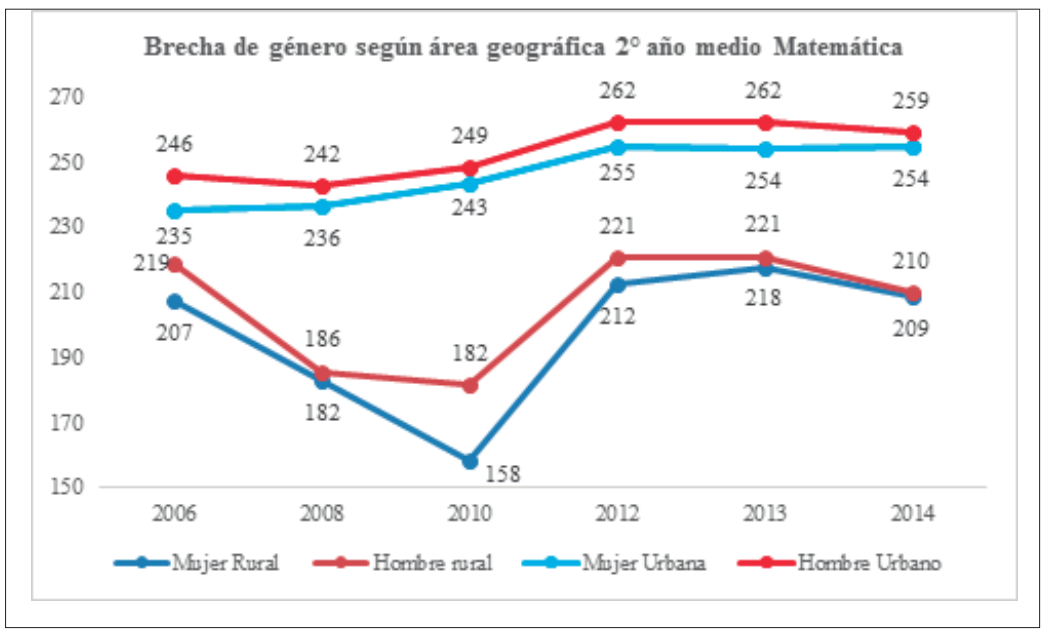

Fuente: Elaboración propia. 

EL SIMCE Y EL ANDROCENTRISMO EN EL DISCURSO DE DOCENTES DE LENGUAJE Y MATEMÁTICA - M. C. Fernández y S. Hauri

En el Gráfico 4 se observa que la BG en establecimientos urbanos disminuyó casi en un 50\%, aunque sigue siendo significativa (cinco puntos). Entre estudiantes del sector rural la BG es de un punto, en parte, por el descenso experimentado por los hombres en el último año.

\section{b. BG según dependencia del establecimiento}

El análisis de la BG según dependencia del establecimiento arroja que las niñas de $4^{\circ}$ año básico de establecimientos particulares sin subvención del Estado logran mejores resultados en algunas mediciones. En los demás establecimientos la diferencia entre niños y niñas es poco significativa. En $8^{\circ}$ año básico y $2^{\circ}$ año medio, en cambio, los hombres superan a las mujeres en todos los establecimientos y las brechas son más profundas en colegios privados. En estos dos niveles la BG se incrementa a medida que se logran resultados más altos.

\section{c. BG y grupo socioeconómico (GSE)}

Del análisis se desprende que las niñas de $4^{\circ}$ año básico de colegios de GSE alto superaron a los niños en ocho puntos en el año 2014. En los demás GSE el rendimiento de niños y niñas es similar. Por su parte, en $8^{\circ}$ año básico y $2^{\circ}$ año medio los hombres logran puntajes más altos que las mujeres en todos los GSE. En el primer caso la brecha no registra mayores diferencias entre GSE. En $2^{\circ}$ año medio, en cambio, es más significativa entre estudiantes que obtienen puntajes más altos (GSE medio y alto).

\section{d. Pueblo mapuche y BG}

En el año 2014 la matrícula indígena representó el 27\% del total de la región. El 99\% corresponde a estudiantes mapuche. Por niveles escolares se observa que el $25 \%$ de los estudiantes de $4^{\circ}$ año básico es mapuche. Este porcentaje aumenta en $8^{\circ}$ año básico (28\%) y $2^{\circ}$ año medio (27\%). En $4^{\circ}$ año básico la mayoría de los estudiantes mapuche asiste a establecimientos rurales (54\%), mientras en $2^{\circ}$ año medio la mayor parte estudia en el sector urbano (85\%). En $8^{\circ}$ año básico el $40 \%$ lo hace en el sector rural. Más del 80\% de los estudiantes mapuche de todos los niveles escolares se concentra en establecimientos de GSE bajo y medio bajo. 
En $4^{\circ}$ año básico existe una marcada diferencia entre los puntajes promedio obtenidos por estudiantes mapuche y no mapuche. Lo mismo ocurre en el análisis de las otras variables: son las niñas mapuche quienes mantienen los puntajes promedio más bajos a lo largo de las mediciones.

En $8^{\circ}$ año básico la BG presenta una tendencia similar en estudiantes mapuche y no mapuche en las distintas mediciones (Gráfico 5). La diferencia, al igual que en los otros niveles escolares, se presenta en los 20 puntos que separan a niños y niñas mapuche de los no mapuche. De esta manera se configura una escala jerárquica que sitúa a las niñas en el nivel más bajo, seguidas de los niños del mismo grupo indígena. Más arriba se ubican las niñas no mapuche y, finalmente, los niños no mapuche.

Gráfico 5. Brecha de género $8^{0}$ año básico pertenencia pueblo mapuche Matemática

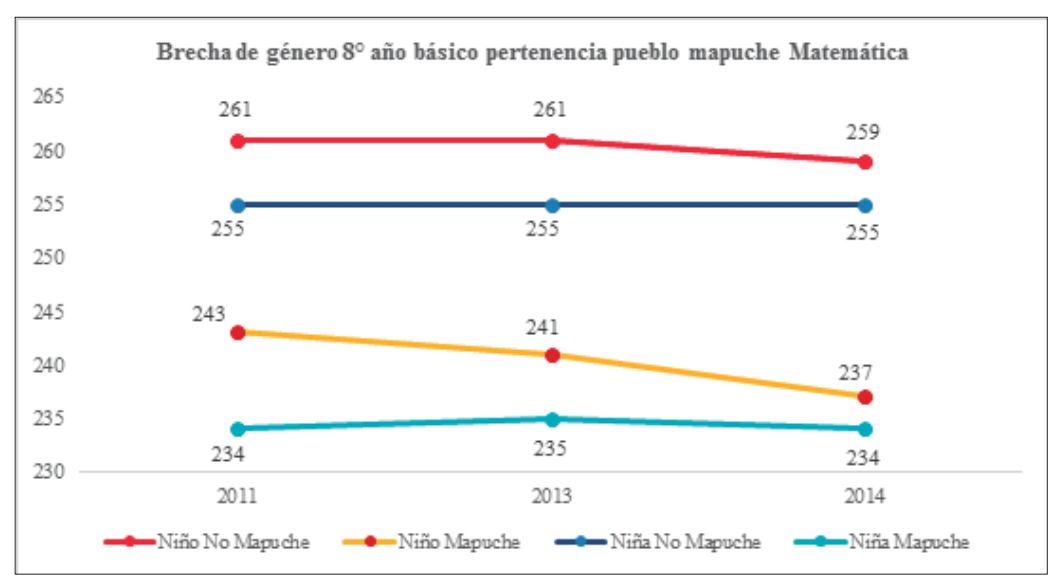

Fuente: Elaboración propia.

En $2^{\circ}$ medio la diferencia en los promedios entre estudiantes mapuche y no mapuche es más profunda (Gráfico 6). Así, el año 2014 las niñas mapuche obtuvieron en promedio 25 puntos menos que sus pares no mapuche. En el caso de los niños mapuche y no mapuche la distancia es más significativa (27 puntos). 
70 RESUltados DE APRENDIZAJE EN LA ARAUCANíA. LA BRECHA DE GÉNERO EN EL SIMCE Y EL ANDROCENTRISMO EN EL DISCURSO DE DOCENTES DE LENGUAJE Y MATEMÁTICA - M. C. Fernández y S. Hauri

Gráfico 6. Brecha de género $2^{\circ}$ año medio según pertenencia al pueblo mapuche Matemática

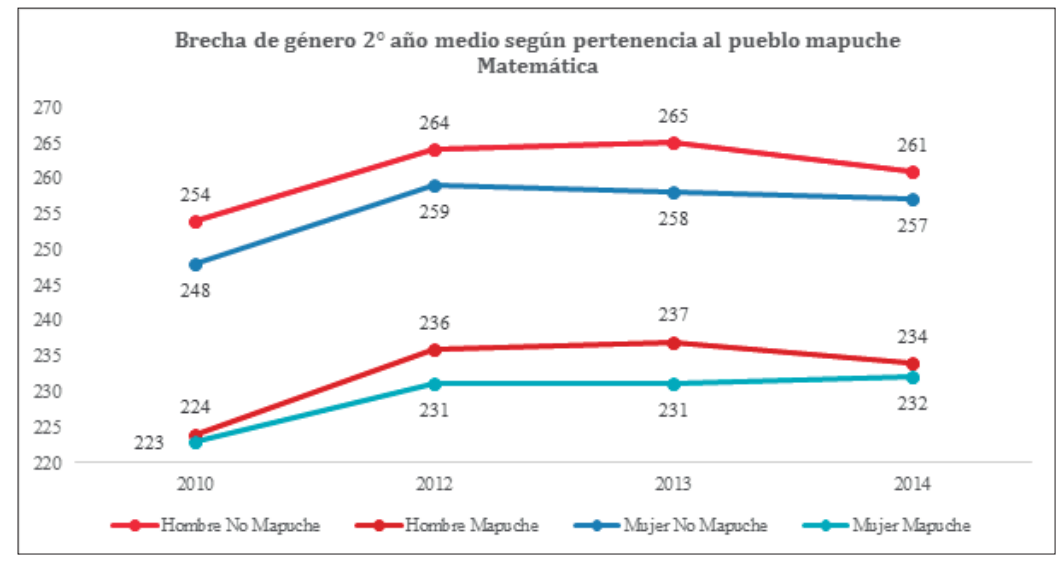

Fuente: Elaboración propia.

El Gráfico 6 revela que la BG es ligeramente superior entre estudiantes que logran mejores resultados (no mapuche). Los estudiantes mapuche, hombres y mujeres, han incrementado su puntaje en 10 puntos entre la primera y la última medición. En ambos grupos el cierre de la BG se ve favorecido por el descenso de los puntajes de los hombres en el último año.

Los resultados presentados muestran que en La Araucanía la BG en Matemática sigue la tendencia nacional. En $4^{\circ}$ año básico se presenta la brecha más discreta en las distintas mediciones hasta cerrarse el año 2014. Los hallazgos revelan, además, que en $8^{\circ}$ año básico y en $2^{\circ}$ año medio el cierre de la brecha está favorecido por una disminución en el puntaje de los hombres en los últimos años. Finalmente tanto en $8^{\circ}$ año básico como en $2^{\circ}$ año medio la BG es más sensible en los establecimientos que logran mejores desempeños.

\subsection{BG en lectura}

En las evaluaciones de Lectura la brecha se revierte a favor de las mujeres. A diferencia de lo que ocurre en Matemática, la distancia entre niños y niñas junto con ser más profunda, presenta un aumento sostenido a lo largo de los años en $4^{\circ}$ año básico y en $2^{\circ}$ año medio y se mantiene en $8^{\circ}$ año básico. 
En $4^{\circ}$ año básico la BG de siete puntos registrada el 2006 aumentó a 13 puntos el 2014. En $8^{\circ}$ año básico, en tanto, la brecha no ha experimentado variaciones y se mantiene en 12 puntos.

En $2^{\circ}$ año medio (Gráfico 7) se observa una situación similar a la de $4^{\circ}$ año básico. La brecha de nueve puntos del año 2006 aumentó a 13 puntos en el 2014. Como en $8^{\circ}$ año básico, en este nivel escolar también se registra una significativa disminución en hombres y mujeres desde el año 2013.

Gráfico 7. Brecha regional de género $2^{0}$ año medio Lectura

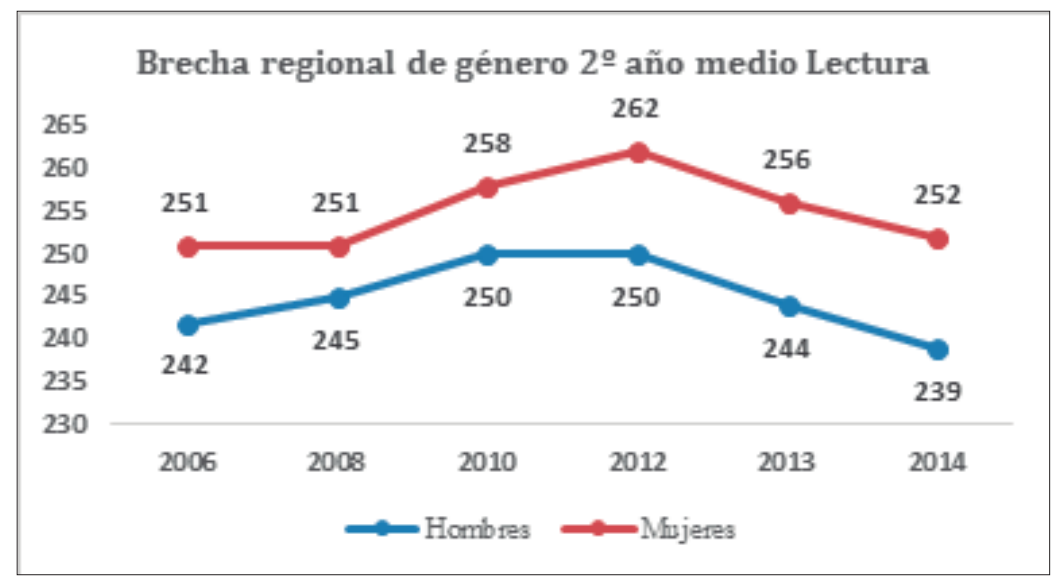

Fuente: Elaboración propia.

a. BG según área geográfica

En Lectura la BG presenta un comportamiento similar entre establecimientos del sector urbano y rural.

En $4^{\circ}$ año básico la BG tiende a aumentar en establecimientos urbanos y rurales. Por su parte, en $8^{\circ}$ año básico (Gráfico 8) se observa que la BG es ligeramente superior entre estudiantes del sector rural. 
72 RESULTADOS DE APRENDIZAJE EN LA ARAUCANÍA. LA BRECHA DE GÉNERO EN EL SIMCE Y EL ANDROCENTRISMO EN EL DISCURSO DE DOCENTES DE LENGUAJE Y MATEMÁTICA - M. C. Fernández y S. Hauri

Gráfico 8. Brecha de género según área geográfica $8^{0}$ año básico Lectura

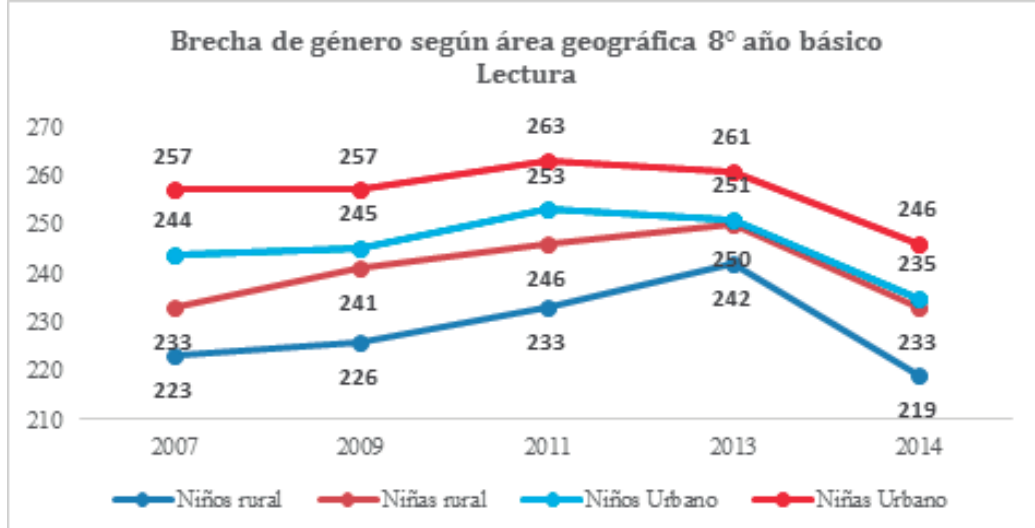

Fuente: Elaboración propia.

El Gráfico 8 también muestra que las niñas rurales mantienen el mismo puntaje en la primera y en la última medición, mientras que los estudiantes de los demás grupos disminuyeron su puntaje. Al respecto, se observa que son las niñas urbanas quienes presentan la baja más significativa a lo largo del período (11 puntos). En cuanto a la BG se aprecia que en el sector rural aumentó de 10 a 14 puntos entre 2007 y 2014 y en el sector urbano disminuyó de 13 a 11 puntos.

En $2^{\circ}$ año medio, la distancia entre los puntajes de niños y niñas es similar en establecimientos urbanos y rurales. En ambos casos la BG aumentó de siete a 13 puntos entre 2006 y 2014. En este nivel educacional hombres y mujeres del sector rural presentaron una significativa disminución en sus puntajes promedio en el período: las mujeres bajaron 11 puntos, mientras los hombres descendieron en 17 puntos. En el sector urbano, en tanto, las mujeres subieron tres puntos y los hombres disminuyeron dos puntos.

\section{b. BG según dependencia del establecimiento}

En los tres niveles educacionales las mujeres superan ampliamente a los hombres en establecimientos municipales, particulares subvencionados y particulares pagados. En el caso de $4^{\circ}$ año básico la BG más profunda se registró en los colegios privados, donde las niñas lograron una ventaja de 18 puntos en el año 2014. En 
establecimientos municipales la brecha fue de 14 puntos y en los particulares subvencionados fue de 11 puntos. En $8^{\circ}$ año básico se observa una tendencia distinta: en establecimientos particulares pagados y particulares subvencionados la brecha fue de 10 puntos, mientras que en establecimientos municipales alcanzó 14 puntos en el 2014. Finalmente, en $2^{\circ}$ año medio (Gráfico 9), al igual que en $4^{\circ}$ año básico, son los establecimientos privados los que exhiben la BG más significativa (21 puntos en 2014). Los particulares subvencionados y los municipales registraron una BG de $14 \mathrm{y}$ 10 puntos respectivamente.

Gráfico 9. Simce Lectura $2^{\circ}$ año medio según dependencia establecimiento

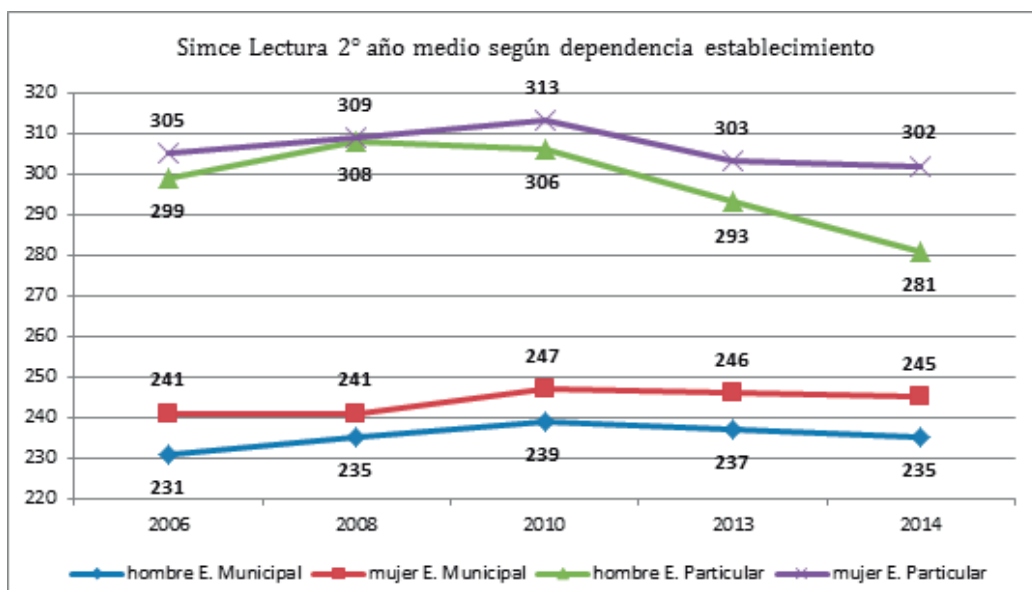

Fuente: Elaboración propia

Los datos revelan que mientras en el sector municipal hombres y mujeres de $2^{\circ}$ año medio registran un ligero incremento entre la primera y la última medición, en el sector privado -donde se concentran los estudiantes con mejores desempeños- los hombres experimentan una disminución de 18 puntos.

\section{c. BG y GSE}

Del análisis de los datos se desprende que en el año 2014 la BG más significativa entre estudiantes de $4^{\circ}$ año básico se presentó en establecimientos de GSE alto (19 puntos) y de GSE medio alto 

EL SIMCE Y EL ANDROCENTRISMO EN EL DISCURSO DE DOCENTES DE LENGUAJE Y MATEMÁTICA - M. C. Fernández y S. Hauri

(15 puntos). En instituciones de GSE medio, medio bajo y bajo fue de 11,13 y 12 puntos respectivamente. En $2^{\circ}$ año medio la BG más profunda también se registró entre estudiantes de GSE alto (18 puntos). En los GSE medio alto y medio bajo fue de 11 puntos, mientras en los GSE medio y bajo fue de ocho y siete puntos respectivamente. Así, en $4^{\circ}$ año básico y en $2^{\circ}$ año medio la BG en el área de Lenguaje es significativa en establecimientos de todos los GSE, no obstante se incrementa en aquellos donde se logran mejores desempeños. En $8^{\circ}$ año básico, en tanto, se da una tendencia distinta de los dos niveles descritos: la BG es más alta en establecimientos de GSE bajo (15 puntos), le siguen los de GSE medio bajo (11 puntos) y alto (10 puntos), y los GSE medio (ocho puntos) y medio alto (cinco puntos).

\section{d. BG según pertenencia al pueblo mapuche}

En los tres niveles educacionales los niños mapuche presentan los más bajos rendimientos en la prueba de lectura, a la vez que las niñas no mapuche son quienes alcanzan los puntajes promedio más altos. En $8^{\circ}$ año básico y en $2^{\circ}$ año medio la BG registrada el 2014 es similar entre estudiantes mapuche y no mapuche (13 y 12 puntos respectivamente). En $4^{\circ}$ año básico, en tanto, la BG es superior entre estudiantes mapuche (Gráfico 10).

Gráfico 10. Brecha de género $4^{0}$ año básico según pertenencia a pueblo mapuche Lectura

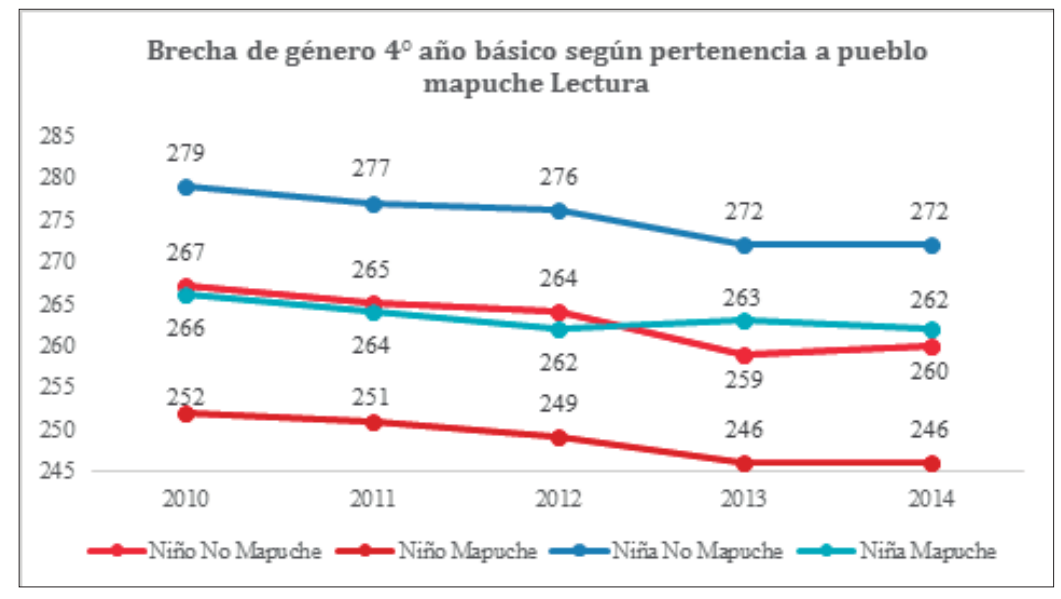

Fuente: Elaboración propia. 
Los resultados presentados son coincidentes con la investigación nacional e internacional en orden a que la BG en Matemática tiende a disminuir mientras que en Lectura va en aumento, lo que demuestra la escasa atención que se ha puesto en esta área de aprendizaje (Perdomo y Puy, 2012). No obstante lo anterior, en La Araucanía se observa que -en parte- la BG en Matemática ha decrecido producto de una moderada disminución en el puntaje de los hombres. Por otra parte, el análisis evidenció que el sexo de los estudiantes no constituye el único factor de desigualdad, pues las dinámicas de exclusión en el sistema escolar se profundizan con la convergencia de otras identidades. De esta forma, se generan intersecciones entre distintas categorías de desigualdad que impactan de manera estructural en las oportunidades políticas, económicas y sociales (Lombardo y Verloo, 2010). En el caso de los resultados de aprendizaje, los puntos críticos de intersección están configurados por las categorías mujer, rural, mapuche y GSE bajo en el caso de Matemática; y hombre, rural, mapuche y GSE bajo en el caso de Lectura.

La evidencia internacional y nacional demuestra que los resultados diferenciados de niños y niñas según áreas de aprendizaje se explican por factores culturales asociados con la transmisión de estereotipos de género, las creencias y las expectativas docentes, entre otros aspectos. Por esta razón, el siguiente apartado analiza, desde el Modelo de Valoración, la presencia de sesgos androcéntricos en el discurso de docentes de Matemática y Lenguaje.

\subsection{Los discursos docentes}

3.3.1. De la renuencia al reconocimiento de la BG en los resultados de aprendizaje

La mayoría de los docentes declara no tener información respecto de la existencia de BG en el Simce. Asimismo, los profesores señalan que en sus respectivos establecimientos predomina el interés por el análisis general para establecer comparaciones entre un año y otro.

Los siguientes ejemplos muestran que los significados que dominan el discurso son la renuencia, el desinterés o la falta de información y la existencia de una idea imprecisa: 

EL SIMCE Y EL ANDROCENTRISMO EN EL DISCURSO DE DOCENTES DE LENGUAJE Y MATEMÁTICA - M. C. Fernández y S. Hauri

1) Tampoco me interesaba, para mí no era relevante saber si los hombres eran más eficientes en contestar un Simce que una mujer, esa es como una manera de discriminación encuentro $\mathrm{yo}^{7}$. (DM, G 4, +BG) $)^{8}$.

-va AFECTO Insatisfacción, -APRECIACIÓN Valuación, +va JUICIO Estima Social: Capacidad, -va JUICIO Sanción Social: Integridad ${ }^{9}$.

2) Nunca, incluso me sorprende, porque sin ir más allá y sin que se siente mal el tema de hombres o mujeres me suena como hombres acá, mujeres allá. Como una división y lo que nosotros estamos trabajando acá también en el colegio es la inclusión y estamos en este año con más fuerza en relación a eso, entonces que digan así como de cierta manera es estar haciendo grupos y discriminando tal vez (DL, G 1, -BG).

-va AFECTO inseguridad, - va AFECTO Infelicidad, +va JUICIO Sanción Social: Integridad, - va JUICIO Sanción Social: Integridad.

En los ejemplos (1) y (2) se expresa renuencia frente al planteamiento de una BG en los resultados de aprendizaje. En ambos casos, la ACTITUD se construye con significados de AFECTO negativos que reflejan falta de interés y sorpresa. Además, por medio de JUICIOS de Sanción Social (Integridad) las entrevistadas relacionan el análisis diferenciado por sexo con una discriminación negativa que podría atentar contra la inclusión y la equidad en la educación. Estos discursos de renuencia pueden contribuir a mantener la estratificación de género. Sin embargo, en ambos casos las docentes abren el espacio dialógico a través del proceso mental "encuentro" (ejemplo 1) y del modalizador de probabilidad "tal vez" (ejemplo 2). En este último caso, desde la perspectiva de la modalidad dialógica (White, 2003), la probabilidad se

7 Los significados valorativos se distinguen con negrita normal para la ACTITUD inscrita y negrita cursiva cuando es evocada. Para la GRADACIÓN se usa subrayado (Fuerza) y cursiva subrayada (Foco). Para la combinación de significados de ACTITUD y GRADACIÓN se emplea negrita subrayada.

8 Entre paréntesis se identifica al entrevistado: DM (docente Matemática), DL (docente Lenguaje); G 1,2,3 o 4 (grupo según la clasificación de establecimientos del estudio); y +BG o-BG (establecimiento con más o menos brecha de género).

9 En el análisis se emplea: + va (valoración positiva) o - va (valoración negativa) para identificar la evaluación del subsistema de ACTITUD (AFECTO, JUICIO o APRECIACIÓN) y su respectivo significado específico. 
concibe en el contexto de una relación social de comunicación, donde los hablantes expresan proposiciones susceptibles de ser discutidas.

3) Realmente no he puesto atención, no sé si ha salido, no he puesto atención, si las niñas o los niños tienen mayor o menor puntaje (DM, G 1, + BG).

-va AFECTO: Insatisfacción, +/- va JUICIO Estima Social: Capacidad.

4) En cuanto a las diferencias no, solamente los resultados que han ido ... bueno, bajaron consecutivamente durante años, pero el último año logramos subir un tanto en el puntaje, pero en cuanto al género, no, no tengo la información (DL, G 3, + BG).

-va APRECIACIÓN Valuación, + JUICIO Estima Social: Capacidad, -va AFECTO: Insatisfacción.

A diferencia de los ejemplos anteriores, en el (3) y (4) la ACTITUD se expresa de manera evocada, a través de significados de AFECTO negativo asociados a desinterés y falta de información. En ambos casos, además, se expresan JUICIOS de Estima Social de Capacidad positivos y negativos hacia los/as estudiantes por su desempeño en las pruebas.

5) Yo tengo entendido que las mujeres son más humanistas comparados con los varones que son más científicos o se inclinan más por las áreas de las matemáticas (DM, G 4, + BG).

+/-va JUICIO Estima Social: Capacidad, + AFECTO Satisfacción.

6) Entonces ahí uno se va enterando del tema de la brecha, de que las mujeres son coloquialmente más buenas para leer o escribir que los hombres (DL, G 4, -BG).

+ va JUICIO Estima Social: Capacidad.

En los ejemplos (5) y (6) los docentes expresan algún grado de conocimiento respecto de la BG. En el primer caso se construye una valoración evocada en relación con las habilidades de hombres y mujeres que no contiene una evaluación positiva o negativa directa (más humanistas/más científicos). En el segundo caso, en cambio, se expresa un JUICIO de Estima Social de Capacidad inscrito hacia las mujeres respecto de sus habilidades para leer o escribir. En ambos 

EL SIMCE Y EL ANDROCENTRISMO EN EL DISCURSO DE DOCENTES DE LENGUAJE Y MATEMÁTICA - M. C. Fernández y S. Hauri

ejemplos los entrevistados abren, implícitamente, sus opiniones a otros puntos de vista con las expresiones "yo tengo entendido" y "uno se va enterando".

Aun cuando predomina la renuencia y el desinterés de los docentes respecto de la BG en el Simce, al momento de abordar concretamente el rendimiento de hombres y mujeres en las asignaturas ellos logran identificar habilidades diferenciadas en hombres y en mujeres que favorecen o dificultan su desempeño.

\subsubsection{Evaluación de habilidades de niños y niñas: la lógica de oposiciones binarias}

En el discurso de los docentes (sin distinción de sexo, edad o tipo de establecimiento) se observan elementos comunes respecto de la valoración de las capacidades de hombres y mujeres, consistentes con la polaridad de los estereotipos de género socialmente establecidos. Así, las habilidades para las matemáticas reconocidas por los docentes se asocian a la rapidez en el caso de los hombres y al orden y la perseverancia en el caso de las mujeres.

7) Pero, bueno es que uno ve que las niñas son más... se dedican más, son más ordenadas que los niños, los niños no, y las niñas siempre tienen un orden, tienen su horario, tienen sus materiales, cumplen con sus útiles escolares como corresponde, pero los niños no, llegan a principio de año, cada niño tiene su estuche con todos sus materiales, pero llevan dos semanas ya no tienen lápiz, no tienen goma, no tienen sacapuntas... (DM, G 1, + BG). +va JUICIO Estima Social: Tenacidad, -va JUICIO Estima Social: Tenacidad.

8) Yo valoro mucho el orden de las niñas, me encanta ver un cuaderno de una alumna porque es un cuaderno con colores, es un cuaderno estructurado, es un cuaderno que yo puedo ir y buscar por ejemplo, qué contenidos vimos la semana anterior y voy a encontrarlos porque sé que es un cuaderno ordenado, creo que eso favorece mucho a las chicas (DM, G 3, + BG).

+va JUICIO Estima Social: Tenacidad, + va AFECTO: Felicidad, APRECIACIÓN Composición: Balance. 
9) No, participan igual, además la mujer es como más ordenada, más metódica que el varón, el varón no lleva como un orden, no es ordenado en sus cuadernos, pero son más rápidos en la resolución de problemas, yo he visto que como que despierta más el hombre en eso, eso lo he notado yo, como diferente entre hombres y mujeres, que el hombre es como más rápido en resolver problemas. (DM, G 4, + BG) ${ }^{10}$.

+va JUICIO Estima Social: Tenacidad, -va JUICIO Estima Social: Tenacidad, +va JUICIO Estima Social: Capacidad.

En los tres ejemplos anteriores ( 7,8 y 9), la ACTITUD se expresa principalmente por medio de JUICIOS positivos de Estima Social de Tenacidad hacia las niñas en referencia a la dedicación, al orden y a la constancia como factores que favorecen su desempeño en Matemática. En un caso (ejemplo 8) se construyen significados de APRECIACIÓN para valorar el material (cuaderno) de las niñas. En relación a los hombres se inscriben JUICIOS de Estima Social de Capacidad positivos donde el atributo que más se reconoce es la rapidez.

En general, la ACTITUD se intensifica con significados de Fuerza de cantidad y de tiempo. En algunos casos, se emplea la conjunción "como" que opera como un atenuador de la valoración ("es como más ordenada"). Por otra parte, se observa que los discursos tienden a la heteroglosia, principalmente por medio de procesos mentales ("uno ve", "sé") que, de modo implícito, expresan una posición susceptible de ser contrastada con otros puntos de vista.

Finalmente, las condiciones que se atribuyen como favorecedoras en el caso de las niñas (orden, constancia y dedicación), se presentan como carencias de los niños. Como contrapunto, la principal capacidad que se reconoce a los niños (rapidez) tiende a presentarse como un déficit en el caso de las niñas, a través de JUICIOS de Estima

10 Para distinguir los significados de la valoración, se empleará: negrita normal cuando la ACTITUD esté inscrita y negrita cursiva cuando esté evocada. En el caso de la GRADACIÓN, se usará subrayado para los valores de Fuerza y cursiva subrayada para los de Foco. En los casos en que se combinen significados de ACTITUD y de GRADACIÓN se empleará negrita subrayada. 
Social de Capacidad negativos inscritos o evocados. Esta forma de construir discursos sobre las habilidades de hombres y mujeres en el aprendizaje de la matemática entraña una perspectiva androcéntrica, en la medida en que enfatiza la distinción estratificada y binaria entre lo femenino y lo masculino.

\subsubsection{Capacidad y tenacidad para Matemática versus gusto e} interés para Lenguaje

A diferencia de lo que ocurre en Matemática, donde los/as docentes tienden a construir explicaciones sobre los desempeños desiguales entre hombres y mujeres con JUICIOS de Estima Social de Capacidad (niños) y de Tenacidad (niñas), en lenguaje las explicaciones se centran en cuestiones actitudinales y de motivación. Así, en los discursos predominan los significados de AFECTO no autorial asociados a Felicidad y Seguridad.

10) Es que yo me he dado cuenta que, por ejemplo, a los niños no les gusta leer mucho (...) y a las niñas les interesa más la lectura, se motivan más las niñas, los niños no es mucho (DL, G 2, -BG). -va AFECTO Felicidad, +va AFECTO Felicidad

En opinión de los docentes las niñas muestran mayor interés y disposición frente a la asignatura de Lenguaje y Comunicación, lo cual explicaría su mejor desempeño. En el ejemplo 10 la ACTITUD se construye por medio de significados de AFECTO no autorial (Felicidad), intensificados (Fuerza), que oponen el interés de las niñas al desinterés de los niños.

11) Es que veo que las mujeres están con una predisposición distinta a mi asignatura, a Lenguaje en general y veo a las niñas más interesadas y que les va mejor, tienen mejor letra, ellas mismas se creen el cuento que son mejores en Lenguaje, será porque son más sentimentales, la verdad es que no lo sé, están como más motivadas, más predispuestas ... y los chiquillos no les gusta, uno les entrega una antología poética y nooo y noooo, no quieren leer poemas, no saben declamar poesía... no les gusta, encuentran que ... ay... se empiezan a reír, que no sé pu', que 
es de homosexual, o que le sale muy afeminado o que no les gusta. (DL, G4, + BG).

+va AFECTO Felicidad, +va APRECIACIÓN Composición Balance, +va AFECTO Seguridad, +va AFECTO Felicidad, -va AFECTO Infelicidad, -va JUICIO Estima Social Capacidad, -va AFECTO Inseguridad.

12) Las niñas le temen menos a equivocarse al señalar un punto de vista, un argumento, en cambio los hombres tienen el miedo $\underline{\text { como }}$ a errar en las respuestas y a lo mejor a esperar una burla de parte también de compañeros del mismo género... uno ve por ejemplo que pasa un niño adelante a declamar un poema, un joven, y no falta el compañero del mismo género que se burla lo que sí, por ejemplo, es bien visto por las niñas (DL, G 3, + BG).

+va AFECTO Seguridad, -va AFECTO Inseguridad, +va AFECTO: Felicidad

El ejemplo (11) evidencia la acumulación de significados valorativos asociados al rendimiento de niños y niñas en Lenguaje. En primer término se construyen significados evocados de AFECTO (Felicidad) que posteriormente se inscriben e intensifican. También se integra un significado de APRECIACIÓN para valorar "la letra" de las niñas como factor favorecedor de un buen desempeño. Por otra parte, el docente asocia el buen rendimiento de las niñas con un estereotipo de género socialmente asignado a las mujeres e históricamente negado a los hombres (sentimentalismo). Además, para explicar la desventaja en el rendimiento de los niños se expresan valoraciones negativas de AFECTO asociadas a interés y motivación y algunas que dan cuenta del significado que los estudiantes le atribuyen a ciertas actividades. Esto último, también reflejado en el ejemplo (12), se relaciona con la disposición de niños y niñas frente al género lírico, el cual provocaría sentimientos diferenciados. En este sentido, a juicio de los docentes, las mujeres se muestran más motivadas e interesadas, mientras a los niños les produce inseguridad por las posibles reacciones de sus pares del mismo sexo.

Además de la recurrencia de significados de AFECTO para explicar el desempeño en Lenguaje, las valoraciones no autoriales 
82 RESUltados DE APRENDIZAJE EN LA ARAUCANÍA. LA BRECHA DE GÉNERO EN EL SIMCE Y EL ANDROCENTRISMO EN EL DISCURSO DE DOCENTES DE LENGUAJE Y MATEMÁTICA - M. C. Fernández y S. Hauri

construidas por los docentes son reveladoras del arraigo de los estereotipos de género entre estudiantes, lo que podría operar como obstaculizador para el desempeño de los hombres en el área de Lenguaje y Comunicación.

3.3.4. Roles de género y expectativas de docentes para el futuro de sus estudiantes

Las expectativas que expresan los docentes de todos los establecimientos educacionales respecto del futuro de sus estudiantes están directamente relacionadas con la asignación social de roles de género. Solo se presentan elementos diferenciadores en establecimientos rurales y urbanos de GSE bajo, asociados con factores sociales y económicos que podrían incidir en los niveles educacionales, pero no en los ámbitos de desempeño esperados para niños y niñas.

13) Yo espero que ellos tengan su enseñanza básica y media completa y lo que a mí me gustaría que ellos aspiren, más que la universidad... los técnicos, Chile necesita muchos técnicos y les va bien a los técnicos y es más fácil acá en la zona hay muchos colegios técnicos, es más fácil que ellos estudien ahí que ... que puedan estudiar en una universidad. Yo sé que tal vez algunos de los míos puede llegar (DM, G 1, + BG).

+va AFECTO Felicidad, +va + APRECIACIÓN Valuación, +va JUICIO Estima Social Capacidad.

14) Algo técnico que tuviera que ver, a lo mejor, si les gusta el campo, relacionado con el contexto agrícola más que nada, o algo de..., bueno los chicos igual lo que les llama la atención son los vehículos, entonces igual algo de mecánica pudiera ser, no sé muy (...), pero el tema de mecánica sí, y el deporte, que les gusta mucho, pero para ser un deportista igual tienen que estudiar, tenemos niños que son así que les va mal aquí en clase, pero están en un club deportivo, pero igual tienen que cumplir (DM, G 1, -BG).

+va AFECTO Felicidad, - va AFECTO Felicidad.

En los ejemplos (13) y (14) los docentes construyen significados de AFECTO en relación con sentimientos futuros de sí mismos y de 
los estudiantes. Como se mencionó antes, las expectativas acerca del futuro de niños y niñas de sectores rurales y de establecimientos urbanos de GSE bajo están influenciadas por la situación social y económica. Aun cuando se expresa esta limitación en el discurso, de igual manera se establecen distinciones basadas en la división sexual del trabajo.

En los establecimientos de los grupos 3 (GSE medio) y 4 (GSE alto) los docentes esperan que hombres y mujeres continúen estudios universitarios. De igual manera como ocurre en los establecimientos de los grupos 1 y 2 , las expectativas son diferenciadas en función de la división sexual de roles:

15) Siempre los oriento a las carreras científicas a los varones, ojalá ingeniería y a las mujeres yo me voy para el área de la salud, que van a encontrar trabajo, yo estoy pendiente, qué sacan con ser profesionales cesantes (...) (DM, G 4, + BG). +va APRECIACIÓN Valuación, -va APRECIACIÓN Valuación.

El ejemplo (15) muestra la valoración diferenciada que los docentes asignan a las carreras profesionales según áreas del conocimiento. Por una parte, se construyen significados positivos de APRECIACIÓN hacia las carreras científicas (ingenierías y medicina) $\mathrm{y}$, de manera evocada, se valoran negativamente las del área humanista ("qué sacan con ser profesionales cesantes"). Por otra parte, se evidencia la segregación de género contenida en las expectativas.

16) A futuro, bueno a los varones yo los veo si son buenos, por ejemplo, si les gustan las matemáticas, si están en ese ámbito, yo los veo siendo ingenieros, por ejemplo. A las niñas las veo siendo parte del ámbito de la medicina (...). Sí, los veo como futuros ingenieros, como futuros, no sé, como pertenecientes a alguna rama del Estado. Y a las niñas las veo siendo, por ejemplo, una alumna del área de la salud. Por ejemplo, buscando trabajo como nutricionista, no sé puede ser fonoaudiología, distintas áreas que las lleven a eso, por un tema de que... el orden, de responsabilidad, o por un tema de preocupación, las niñas son muy preocupadas en todo aspecto, en lo global, de sus 

EL SIMCE Y EL ANDROCENTRISMO EN EL DISCURSO DE DOCENTES DE LENGUAJE Y MATEMÁTICA - M. C. Fernández y S. Hauri

compañeros, compañeras, están pendientes, los hombres son mucho más relajados, entonces en ese aspecto yo lo veo de esa manera. (DM, G 3, + BG).

+va JUICIO Estima Social: Capacidad, +va AFECTO Felicidad, +va JUICIO Estima Social: Tenacidad, -va JUICIO Estima Social Tenacidad.

De manera similar al ejemplo anterior, en el (16) también se evidencian expectativas diferenciadas según los roles sociales de género. En este caso la ACTITUD respecto del futuro de los niños se construye por medio de JUICIOS de Estima Social de Capacidad y de AFECTO en relación con sus destrezas e interés por la matemática. En el caso de las niñas, en cambio, predominan los significados de Estima Social de Tenacidad que relacionan a las mujeres con los estereotipos tradicionales (orden, responsabilidad, preocupación por los otros) consistentes con los requerimientos de áreas profesionales altamente feminizadas, a la vez que se evoca un JUICIO negativo de Estima Social (Tenacidad) que indicaría que los hombres no disponen de dichas condiciones.

La siguiente tabla sintetiza los patrones valorativos identificados en los discursos:

\begin{tabular}{|c|c|c|}
\hline Sector de aprendizaje & ACTITUD & Atributo/sentimiento \\
\hline \multirow{3}{*}{ Matemática } & $\begin{array}{l}\text { + JUICIO Estima Social Capacidad } \\
\text { (niños) } \\
\text {-JUICIO Estima Social Capacidad } \\
\text { (niñas) }\end{array}$ & Rápido/lenta \\
\hline & $\begin{array}{l}\text { +JUICIO Estima Social Tenacidad } \\
\text { (niñas) }\end{array}$ & \multirow{2}{*}{ Perseverancia, orden/desorden } \\
\hline & $\begin{array}{l}\text {-JUICIO Estima Social Tenacidad } \\
\text { (niños) }\end{array}$ & \\
\hline \multirow{3}{*}{ Lenguaje } & +AFECTO Felicidad (niñas) & Gusto, interés, motivación \\
\hline & -AFECTO Infelicidad (niños) & $\begin{array}{l}\text { Desinterés, desmotivación, } \\
\text { disgusto }\end{array}$ \\
\hline & -AFECTO Inseguridad (niños) & Temor a las burlas \\
\hline
\end{tabular}

El discurso de los docentes de Lenguaje y Matemática, de todos los niveles escolares y de todos los establecimientos educacionales contiene sesgos androcéntricos expresados en valoraciones diferenciadas referidas a habilidades y factores que favorecen el 
desempeño de niños y niñas en cada asignatura, así como también en expectativas futuras orientadas por los roles tradicionales de género que predominan en la sociedad chilena.

\section{Conclusiones y recomendaciones}

En La Araucanía, la distancia entre niños y niñas en Matemática se cerró el 2014 en $4^{\circ}$ año básico, mientras se acorta paulatinamente en $8^{\circ}$ año básico y en $2^{\circ}$ año medio. Los datos revelan un avance sustantivo en la materia, a la vez que muestran un importante incremento en el desempeño de las mujeres a lo largo del período estudiado. Esto último podría relacionarse con el interés que ha concitado este sector de aprendizaje en materia de investigación y con la intervención en el currículo escolar y en los materiales didácticos para la enseñanza de la matemática. Sin embargo, resulta necesario poner atención en el comportamiento de la BG en los últimos años, puesto que la reducción que ha experimentado, tanto en $8^{\circ}$ año básico como en $2^{\circ}$ año medio, se sostiene en que las mujeres mantienen sus puntajes y los hombres disminuyen. Esta situación cobra especial importancia en una región que exhibe desempeños muy inferiores a la media nacional.

En Lectura los datos indican que la diferencia entre hombres y mujeres, además de ser profunda, registra un incremento sostenido. Por esta razón, es fundamental profundizar en un área donde existe escasa información y que recién en los últimos años se plantea como preocupación en el debate público. Al respecto es indispensable que las políticas educacionales aborden esta brecha con consideraciones de género, pues en ella (al igual que en Matemática) podrían estar operando factores culturales que impactan negativamente en el desarrollo y las oportunidades futuras de los niños.

A partir de los resultados expuestos se reafirma la importancia de analizar la BG en los aprendizajes desde una perspectiva interseccional, puesto que en la desigualdad educacional operan múltiples categorías de exclusión. Así, ser hombre o mujer no tiene el mismo impacto cuando se integran variables como el área geográfica, el grupo socioeconómico o la pertenencia a un pueblo indígena. Del mismo modo, ninguna de estas categorías explica, por sí sola, los 
resultados de niños y niñas en los distintos sectores de aprendizaje. Más aún, es la convergencia de distintas identidades la que genera una escala jerárquica de exclusión que sitúa a los estudiantes en puntos más o menos críticos y determinantes para sus oportunidades futuras.

En el discurso de los docentes -sin distinción del tipo de establecimiento, nivel escolar en que se desempeñen, ni BG que registre la institución- se identifican sesgos androcéntricos que expresan el arraigo de los estereotipos sexistas en el sistema escolar. Dichos sesgos se develan a través de los recursos lingüísticos empleados para evaluar habilidades de niños y niñas, factores que inciden en el desempeño y expectativas futuras. Estos significados podrían operar en la segregación por áreas del conocimiento, así como también en la posterior elección de una carrera profesional.

Finalmente, en el discurso de los docentes se observa una tendencia heteroglósica a través de recursos que, indirectamente, reconocen la existencia de otros puntos de vista. Esta forma de construir la ACTITUD podría representar una oportunidad para avanzar en la deconstrucción de los patrones valorativos jerárquicamente binarios que dominan el discurso. Para este efecto es fundamental generar estrategias que permitan abrir la discusión en torno a las BG y sus distintas intersecciones al interior de los establecimientos educacionales.

\section{Referencias}

Agencia de Calidad de la Educación. (2013). Esa brecha... Apuntes sobre la calidad de la educación, 1(2), 1-18.

Althusser, L. (1976). Posiciones. Barcelona: Anagramas.

Apple, M. (1986). Ideología y currículo. Madrid: Akal.

Becerra, S. (2011). Valores de equidad y aceptación en la convivencia de escuelas en contexto indígena: la situación del prejuicio étnico docente hacia los estudiantes mapuche en Chile. Revista de Educación, número extraordinario, 163-181.

Bernstein, B. (1990). The structuring of pedagogic discourse. London: Routledge.

Bernstein, B. (1998). Pedagogía, control simbólico e identidad. Madrid: Morata. 
Bourdieu, P. y Passeron, J. C. (1998). La reproducción. Elementos para una teoría de la enseñanza. México D.F.: Fontamara.

Cabezas, G. (2009). ¿Afecta el género de los profesores a los resultados académicos de los estudiantes? Diferencias de género en matemática y lenguaje. Documento de Trabajo CPCE $N^{o}$ 15, Universidad Diego Portales. Recuperado de http:// www.udp.cl/investigacion/repo_listado.asp?pagina=9

Calderón, F. y Matus, C. (2013). Factores asociados con el rendimiento escolar matemática $2^{\circ}$ medio 2012. Agencia de Calidad de la Educación. Documento de Trabajo $\mathrm{N}^{o} 4$. Recuperado de https://s3.amazonaws.com/archivos. agenciaeducacion.cl/documentos-web/Documento_N.\%E2\%81\%B04_ Factores_asociados_con_el_rendimiento_escolar_Matematica_II_ medio_2012.pdf

Cerón, F. y Lara, M. (2011). Factores asociados con el rendimiento escolar Simce 2010, Educación Matemática $4^{\circ}$ básico e Inglés $3^{\circ}$ medio. Agencia de Calidad de la Educación, Documento de Trabajo No 2. Recuperado de http://www. agenciaeducacion.cl/wp-content/uploads/2013/02/Factores-AsociadosSIMCE-2010.pdf

De la Rica, S. y González, A. (2013). Brechas de género en los resultados de PISA: el impacto de las normas sociales y la transmisión intergeneracional de las actitudes de género. Madrid: Fedea.

Del Río, F. \& Strasser, K. (2013). Preschool children's beliefs about gender differences in academic skills. Sex Roles, 68(3-4), 231-238. http:// dx.doi.org/10.1007/s11199-012-0195-6

Díaz, A. (2003). Educación y género. Colección Pedagógica Universitaria, 40, 1-8.

Flores, R. (2007). Representaciones de género de profesores y profesoras de matemática, y su incidencia en los resultados académicos de alumnos y alumnas. Revista Iberoamericana de educación, 43, 103-118.

Gramsci, A. (1981). Cartas desde la cárcel. México: Ediciones Era.

Guerrero, E., Provoste, P., y Valdés, A. (2006). La desigualdad olvidada: género y educación en Chile. En Hexagrama Consultoras, Facultad Latinoamericana de Ciencias Sociales (FLACSO), Instituto de Estudios Sociales Contemporáneos (IESCO) y Universidad Central de Bogotá (Eds.), Equidad de género y reformas educativas Argentina, Chile, Colombia y Perú (99-148). Santiago: Hexagrama Consultoras.

Halliday, M. A. K. (1994). An introduction to functional grammar. London: Arnold.

Halliday, M. A. K. \& Matthiessen, M. I. M. (2014). An introduction to functional grammar. London: Edward Arnold. 
Hood, S. y Martin, J. (2005). Invocación de actitudes. El juego de la gradación de la valoración en el discurso. Signos, 38(58), 195-220. http://dx. doi. org/10.4067/s0718-09342005000200004

Kaplan, N. (2007). La construcción discursiva del evento conflictivo en las noticias por televisión. Universidad Central de Venezuela. Recuperado de http:// www.dissoc.org/recursos/tesis/Tesis\%20Nora\%20Kaplan.pdf.

Lombardo, E. y Verloo, M. (2010). La 'interseccionalidad' del género con otras desigualdades en la política de la Unión Europea. Revista Española de Ciencia Política, 23, 11-30.

Martin, J. R. (2000). Beyond exchange: APPRAISAL Systems in English. En S. Hunston \& G. Thompson (Eds.), Evaluation in text: Authorial stance and the construction of discourse (142-175). Oxford: Oxford University Press.

Martin, J. R. \& Rose, D. (2007). Working with discourse. Meaning beyond the clause. London: Continuum.

Martin, J. R. \& White, P. (2005). The language of evaluation: Appraisal in English. New York: Palgrave Macmillan.

Martínez, F., Martínez, S. \& Mizala, A. (2015). Pre-service elementary school teachers' expectations about student performance: How their beliefs are affected by mathematics anxiety and student gender. Centro de Economía Aplicada Universidad de Chile. Documentos de Trabajo No 310. Recuperado de https://www.dii.uchile.cl/wp-content/uploads/2015/04/ Pre-service-Elementary-School-Teachers-Expectations-About-StudentPerformance-Francisco-Martinez-Salome-Martinez-y-AlejandraMizala.pdf.

Merino, M., Quilaqueo, D., y Saiz, J. (2008). Una tipología del discurso de discriminación percibida en mapuches de Chile. Signos, 41(67), 279297. http://dx.doi.org/10.4067/s0718-09342008000200011

Ministerio de Desarrollo Social. (2016). CASEN 2015. Situación de la pobreza en Chile. Recuperado de http://observatorio.ministeriodesarrollosocial. gob.cl/casen-multidimensional/casen/docs/CASEN_2015_Situacion_ Pobreza.pdf

Ministerio de Educación de Chile, Mineduc. (2012). Resultados TIMSS 2011. Estudio internacional de tendencias en matemáticas y ciencias. Santiago. Recuperado de http://www.mineduc.cl/usuarios/acalidad/ doc/201301151653440.Informe_Resultados_TIMSS_2011_Chile_ (10-01-13).pdf

Moreno, A. (2006). Más allá del género: aportaciones no androcéntricas a la construcción de un humanismo plural. En C. Rodríguez Martínez (Comp.), Género y currículo. Aportaciones del género al estudio y práctica del currículo (103-130). Madrid: Akal. 
Oteíza, T. (2009). Solidaridad ideológica en el discurso de la historia: tensión entre orientaciones monoglósicas y heteroglósicas. Signos, 42(70), 219244. http://dx.doi.org/10.4067/s0718-09342009000200004

Oteíza, T. (2011). Representación de las memorias del pasado: intersubjetividad en el discurso pedagógico de la historia. En T. Oteíza y D. Pinto (Eds.), En (re)construcción. Discurso, identidad y nación en los manuales escolares de historia y ciencias sociales (129-172). Santiago: Cuarto Propio.

Perdomo, I. (2010). Reflexiones sobre los estudios de ciencia, tecnología y género. Laguna, 26, 79-93.

Perdomo, I. y Puy, A. (2012). Igualdad de género, democracia y búsqueda del bien común como retos de la ciencia. En I. Perdomo y A. Puy (Eds.), Género, conocimiento e investigación (pp. 169-186). Madrid: Plaza y Valdés Editores.

Rovetto, F. (2010). Androcentrismo y medios de comunicación: apuntes sobre la representación de las mujeres en la prensa de actualidad. Cuadernos de Información, 27, 42-52.

Sau, V. (2000). Diccionario ideológico Feminista. Barcelona: Icaria.

Torres, J. (1998). El currículum oculto. Madrid: Morata.

Organización de las Naciones Unidas para la Educación, la Ciencia y la Cultura, Unesco. (2012). Atlas mundial de la igualdad de género en la educación. Recuperado de http://www.uis.unesco.org/Education/Documents/ unesco-gender-education-atlas-2012-spa.pdf

White, P. (2003). Beyond modality and hedging: A dialogic view of the language of intersubjective stance. Text, 23(2), 259-284. http://dx.doi. org/10.1515/text.2003.011

Recibido: 29/07/2016

Aceptado: 16/10/2016 